Squibb, Celgene, Eli Lilly, Janssen, Merck Sharp \& Dohme, Novartis, Sanofi, UCB, Roche, Pfizer, Beatriz Joven-lbáñez Speakers bureau: Abbvie, Celgene, Janssen, Merck Sharp \& Dohme, Novartis, Pfizer, Wim Noel Employee of: Janssen Pharmaceuticals NV, Michael T Nurmohamed Grant/research support from: Abbvie, Bristol-Myers Squibb, Celltrion, GlaxoSmithKline, Jansen, Eli Lilly, Menarini, Merck Sharp \& Dohme, Mundipharma, Pfizer, Roche, Sanofi, USB, Consultant of: Abbvie, Bristol-Myers Squibb, Celltrion, GlaxoSmithKline, Jansen, Eli Lilly, Menarini, Merck Sharp \& Dohme, Mundipharma, Pfizer, Roche, Sanofi, USB, Speakers bureau: Abbvie, Bristol-Myers Squibb, Celltrion, GlaxoSmithKline, Jansen, Eli Lilly, Menarini, Merck Sharp \& Dohme, Mundipharma, Pfizer, Roche, Sanofi, USB, Petros Sfikakis Grant/research support from: Grant/research support from Abvie, Novartis, MSD, Actelion, Amgen, Pfizer, Janssen Pharmaceutical, UCB, Elke Theander Employee of: Janssen-Cilag Sweden AB, Laure Gossec Grant/research support from: Lilly, Mylan, Pfizer, Sandoz, Consultant of: AbbVie, Amgen, Biogen, Celgene, Janssen, Lilly, Novartis, Pfizer, Sandoz, Sanofi-Aventis, UCB DOI: 10.1136/annrheumdis-2020-eular.2755

\section{FRI0363 $\quad$ CLINICAL PREDICTORS OF SECUKINUMAB RETENTION IN A REAL WORLD COHORT OF PATIENTS WITH PSORIATIC ARTHRITIS AND AXIAL SPONDYLOARTHRITIS}

A. Tindell ${ }^{1}$, A. Mcgucken ${ }^{1}$, S. Batool ${ }^{2}$, S. Siebert ${ }^{1} .{ }^{1}$ University of Glasgow, Institute of Infection, Immunity and Inflammation, Glasgow, United Kingdom; ${ }^{2}$ NHS Greater Glasgow \& Clyde, Glasgow, United Kingdom

Background: There are increasing treatment options for patients with psoriatic arthritis (PsA) and axial spondyloarthritis (AxSpA). Whilst there are several studies identifying predictors of response to TNF inhibitors ${ }^{1}$ there is little data so far predicting response to the IL-17A inhibitor secukinumab which given its different mechanism of action may have different predictors of response.

Objectives: To identify demographic or clinical factors at initiation of secukinumab associated with stopping treatment due to inefficacy in PsA and in AxSpA in a real world cohort.

Methods: Retrospective analysis of all rheumatology patients' notes in Glasgow who had received secukinumab. Demographics, disease activity at baseline and retention of secukinumab were collected from medical records in patients with a diagnosis of PsA or AxSpA. Patients who discontinued due to adverse events or other events (e.g. pregnancy) were excluded. Patients who remain on secukinumab but have not yet had their six-month review to assess response or who started secukinumab via a clinical trial were also excluded. Unpaired T-test of unequal variance used to assess differences between groups with $p$-value $\leq 0.05$ considered significant.

Results: 352 rheumatology patients in Glasgow had ever received secukinumab. 266 had PsA, 76 had AxSpA (others: SAPHO, JIA, reactive arthritis).

77 PsA patients discontinued secukinumab, 48 due to inefficacy. 157 PsA patients remain on secukinumab and have had at least an initial six-month review.

Table 1 shows results for PsA. Inefficacy was associated with higher levels of current smoking and higher levels of ESR and CRP but not tender or swollen joints.

Table 1. Demographics and clinical characteristics of PsA patients starting secukinumab

\begin{tabular}{lccc}
\hline & $\begin{array}{c}\text { Stopped due to } \\
\text { Inefficacy }(\mathrm{n}=48)\end{array}$ & $\begin{array}{c}\text { Remain on Secukinumab } \\
(\mathrm{n}=157)\end{array}$ & $\begin{array}{c}\text { Significance } \\
(\mathrm{p} \text { value })\end{array}$ \\
\hline Gender (M:F) & $1: 1.86$ & $1: 2.3$ & 0.24 \\
Age (years) & 47.8 & 50.8 & 0.078 \\
Current Smoking & $37 \%$ & $21 \%$ & 0.040 \\
Socioeconomic Decile & 4.9 & 5.0 & 0.39 \\
Weight (kg) & 81.6 & 85.9 & 0.11 \\
Number of Comorbidities & 1.72 & 1.85 & 0.31 \\
Disease Duration (years) & 10.4 & 11.2 & 0.24 \\
Number Previous bDMARDs & 1.69 & 1.40 & 0.095 \\
Tender Joint Count & 16.6 & 16.6 & 0.50 \\
Swollen Joint Count & 6.4 & 7.3 & 0.29 \\
Patient Global Score (VAS) & 62.4 & 67.7 & 0.19 \\
ESR (mm/hr) & 24.1 & 14.8 & 0.017 \\
CRP (mg/L) & 12.8 & 6.2 & 0.049 \\
\hline
\end{tabular}

Values are mean unless stated

$21 \mathrm{AxSpA}$ patients discontinued secukinumab, 13 due to inefficacy. $49 \mathrm{AxSpA}$ patients remain on secukinumab and have had at least an initial six-month review. AxSpA patients who stopped due to inefficacy had higher mean BASDAI (8.47 vs 7.02, $p=0.007$ ) but there was no difference in mean ESR (31 vs 27.1, $p=0.31$ ) or CRP (23.6 vs 23.0, $p=0.48$ ). Surprisingly, disease duration was lower in inefficacy group (7.8 years vs $13.5, p=0.003$ ); this could reflect a higher proportion in the inefficacy group with non-radiographic AxSpA which is known to be associated with earlier disease and to have a lower response to biologic treatments than ankylosing spondylitis. Smoking did not show significant difference in $\mathrm{AxSpA}$ but numbers are small and there is numerically higher level of smoking in the inefficacy group ( $58 \%$ vs $32 \%, p=0.063)$. No other significant differences in demographics or clinical characteristics were noted.

Conclusion: Smoking predicted inefficacy in secukinumab in PsA patients, with a similar trend in AxSpA patients, reinforcing the importance of promoting smoking cessation. Higher levels of ESR and CRP negatively predicted secukinumab response in PsA. High BASDAI and low disease duration in AxSpA predicted inefficacy. These clinical factors may be helpful in informing treatment decisions in PsA and AxSpA in the absence of therapeutic biomarkers.

References:

[1] Maneiro JR et al. Predictors of response to TNF antagonists in patients with ankylosing spondylitis and psoriatic arthritis: systematic review and meta-analysis. RMD Open. 2015;1(1):e000017.

Disclosure of Interests: Alistair Tindell: None declared, Andrew McGucken: None declared, Saira Batool: None declared, Stefan Siebert Grant/research support from: BMS, Boehringer Ingelheim, Celgene, GlaxoSmithKline, Janssen, Novartis, Pfizer, UCB, Consultant of: AbbVie, Boehringer Ingelheim, Janssen, Novartis, Pfizer, UCB, Speakers bureau: AbbVie, Celgene, Janssen, Novartis DOI: 10.1136/annrheumdis-2020-eular.5413

\section{FRI0364 PSORIATIC ARTHRITIS: SYSTEMATIC LITERATURE REVIEW AND RESULTS OF THE CARMA COHORT}

A. Urruticoechea-Arana ${ }^{1}$, S. Castañeda ${ }^{2}$, E. Loza $^{3}$, T. Oton $^{3}$, D. Benavent ${ }^{4}$ M. A. Martin-Martinez ${ }^{5}$, M. A. González-Gay ${ }^{6}$ on behalf of CARMA Project Collaborative Group. ${ }^{1}$ H. Can Misses, Ibiza, Spain; ${ }^{2}$ H.U. La Princesa, Madrid, Spain; ${ }^{3}$ InMusc, Madrid, Spain; ${ }^{4}$ H.U. La Paz, Madrid, Spain; ${ }^{5}$ Spanish Society Of Rheumatology, Madrid, Spain; ${ }^{6}$ H.U. Marqués de Valdecilla, Santander, Spain

Background: The cardiovascular burden in psroriatic arthritis (PsA) is well recognized ${ }^{1}$.

Objectives: To analyze the prevalence of metabolic syndrome (MetS) in patients with PsA

Methods: We conducted a systematic literature review (SLR) and a sub-analysis of the CARMA cohort. In the SLR, we searched in Pubmed, Embase, the Cochrane Central Library, and the ClinicalTrial until March 2019 using Mesh terms and free text words. We included SLR, clinical trials and observational studies analyzing the prevalence or frequency of MetS in PsA. Two reviewers selected articles, assessed the quality of the studies and collected data independently. The CARMA cohort was designed to establish the cardiovascular (CV) morbidity and associated risk factors for $\mathrm{CV}$ disease. It includes data from patients with chronic inflammatory rheumatic diseases (including PsA) of 67 Spanish hospitals. A sub-analysis of the prevalence of metS in PsA was performed using the National Cholesterol Education Program Adult Treatment Panel III criteria updated in 2005, which requires the presence of $\geq 3$ of the following: high waist circumference, low HDL cholestero level, high triglyceride level, high blood pressure and high fasting glucose values. Results: A total of 18 articles of moderate to high quality, were selected in the SLR. The included patients presented a balanced distribution by sex with an average age ranging from 42 to 59 years. The frequency of MetS varied from $23.5 \%$ to $62.9 \%$ depending on the definition of MetS. The most widely used classification method was the National Cholesterol Education Program, followed by the method recommended by the International Diabetes Federation in 2009. A total of 724 patients with PsA were included in the CARMA study, of whom 327 (45.4\%) were women and 157 (21.8\%) smokers. The mean age at baseline was $51 \pm 12$ years and the mean duration of PsA disease 9 (4-16) years. Hypertension was the most frequently altered parameter $(66.8 \%)$, followed by fasting glucose $(42.6 \%)$ and hypertriglyceridemia $(30.6 \%)$. Table 1 shows the frequency of patients according to the number of MetS components. A total of $222(30.6 \%)$ PsA patients presented metabolic syndrome.

Table 1. Prevalence of metabolic syndrome.

\begin{tabular}{lcc}
\hline $\begin{array}{l}\text { Number of components } \\
\text { N 0-5 }\end{array}$ & $\begin{array}{c}\text { Patients }(n) \\
\text { CARMA study }\end{array}$ & $\begin{array}{c}\text { Percentage of patients, SLR } \\
(\%)\end{array}$ \\
\hline $\mathbf{0}$ & 101 & 13,95 \\
$\mathbf{1}$ & 208 & 28,73 \\
$\mathbf{2}$ & 193 & 26,66 \\
3 & 151 & 20,86 \\
4 & 59 & 8,15 \\
5 & 12 & 1,66 \\
Total & 724 & 100 \\
\hline
\end{tabular}

Conclusion: The frequency of the individual components of the MetS is variable according to the method of classification, which makes it difficult to compare between studies. In the CARMA study, the prevalence of MetS was around $30 \%$, which supports the control of individual factors to prevent $\mathrm{CV}$ disease. 


\section{References:}

[1] Liew JW, et al. Best Pract Res Clin Rheumatol. 2018;32(3):369-389. Disclosure of Interests: ANA URRUTICOECHEA-ARANA: None declared, Santos Castañeda: None declared, Estíbaliz Loza Grant/research support from Roche, Pfizer, Abbvie, MSD, Novartis, Gebro, Adacap, Astellas, BMS, Lylly Sanofi, Eisai, Leo, Sobi, Teresa Oton Consultant of: Novartis Farmaceutica, SA Pfizer, S.L.U., Merck Sharp \& Dohme España, S.A., Roche Farma, S.A, Sanof Aventis, AbbVie Spain, S.L.U., and Laboratorios Gebro Pharma, SA (All trhough institution), Diego Benavent: None declared, Maria Auxiliadora Martin-Martinez None declared, Miguel A González-Gay Grant/research support from: Pfizer, Abbvie, MSD, Speakers bureau: Pfizer, Abbvie, MSD DOI: 10.1136/annrheumdis-2020-eular.5556

\section{\begin{tabular}{|l|l}
\hline FRI0365 REAL-WORLD EFFECTIVENESS AND SAFETY OF \\
\hline
\end{tabular} APREMILAST IN A LARGE COHORT OF GERMAN PATIENTS WITH PSORIATIC ARTHRITIS: 1-YEAR ANALYSIS OF AN ONGOING MULTICENTER, PROSPECTIVE, NON-INTERVENTIONAL STUDY}

J. Wollenhaupt ${ }^{1}$, H. Strothmeyer ${ }^{2}$, M. Fiene ${ }^{3}$, S. Morys ${ }^{4}$, C. Bach ${ }^{4}$,

J. Roemmler-Zehrer ${ }^{4} .{ }^{1}$ Rheumatologie im Struenseehaus, Hamburg, Germany;

${ }^{2}$ Rheumatologische Gemeinschaftspraxis Düsseldorf, Düsseldorf, Germany;

${ }^{3}$ Klinik für Rheumatologie, Demmin, Germany; ${ }^{4}$ Amgen Inc., München, Germany

Background: Apremilast (APR) has been studied extensively in phase III randomized, controlled trials. However, real-world information is limited on the effectiveness and safety of APR in patients with psoriatic arthritis (PsA).

Objectives: To assess the effectiveness and safety of APR in a large cohort of patients with active PsA from routine clinical practice settings in Germany.

Methods: In this multicenter, prospective, non-interventional study, the primary endpoint was the proportion of patients reaching $\geq 1$ point $(\geq 20 \%)$ improvement from baseline (BL) in the Physician's Global Assessment of Disease Activity (PhGA) score. Other endpoints included effects on swollen and tender joint counts (SJC/TJC), psoriasis-involved body surface area (BSA), enthesitis, dactylitis, Patient's Global Assessment of Disease Activity score (PtGA), Psoriatic Arthritis Impact of Disease (PsAID) tool, pain, and pruritus. The current analysis is based on observed data through 1 year of study duration.

Results: A total of 545 German patients were enrolled and followed up to 12 months of APR treatment; 488 patients were included in the safety analysis and 418 in the full analysis set. The mean age was 55 years, mean body mass index was $29.5 \mathrm{~kg} / \mathrm{m}^{2}$, and $60 \%$ were female. The mean duration of psoriasis and PsA was 26 years and 18 years, respectively. At BL, $46.7 \%$ of patients had enthesitis based on the Leeds Enthesitis Index (LEl; mean [SD]: 2.9 [1.72]) and 23\% had dactylitis (mean [SD]: $2.2 \pm 2.03$ ); $74 \%$ of patients were biologic-naive. Effectiveness is shown after $\sim 1$ month (Visit 1 [V1]) and $\sim 4$ months (Visit 2 [V2]) and for up to 225 patients after 12 months (Visit 5 [V5]) of treatment (Table).

Improvements were also seen in PtGA, overall pain, and pruritus. A subanalysis suggests APR was associated with greater benefits in biologic-naive patients compared with patients who previously received biologic therapy. Observed safety and tolerability through V5 were consistent with the known overall safety profile of APR. Common adverse events in clinical trials were similar, with a lower incidence of diarrhea $(11.1 \%)$, nausea $(7.0 \%)$, headache $(3.9 \%)$, and respiratory tract infection $(0.8 \%)$. Conclusion: Data from this large, real-world cohort of patients with PsA show the effectiveness of APR. In patients with up to 12 months of follow-up, APR was associated with rapid and maintained improvements in physician-assessed and patient-reported outcomes. Safety and tolerability were consistent with the known profile of APR.

Table. Effectiveness of APR Treatment

\begin{tabular}{|c|c|c|c|c|}
\hline & $B L n=418^{*}$ & $\mathrm{~V} 1 \mathrm{n}=326^{\star}$ & V2 $n=360^{*}$ & V5 $n=214^{*}$ \\
\hline $\begin{array}{l}\geq 1 \text {-point PhGA } \\
\quad \text { improvement \% }\end{array}$ & NA & 56.2 & 77.2 & 86.4 \\
\hline $\begin{array}{l}\text { PhGA score, mean } \\
(95 \% \mathrm{Cl})\end{array}$ & $2.5(2.4,2.5)$ & $1.8(1.7,1.9)$ & $1.4(1.3,1.5)$ & $1.1(1.0,1.2)$ \\
\hline PhGA score $=0-1, \%$ & NA & 34.3 & 60.8 & 77.0 \\
\hline $\begin{array}{l}\text { SJC mean improve- } \\
\text { ment, } \%(95 \% \mathrm{Cl})\end{array}$ & NA & $42.1(34.7,49.5)$ & $54.7(45.4,64.1)$ & $75.7(65.5,86.0)$ \\
\hline $\begin{array}{l}\text { TJC mean improve- } \\
\text { ment, } \%(95 \% \mathrm{Cl})\end{array}$ & NA & $38.3(27.2,40.4)$ & $36.0(23.8,48.3)$ & $57.1(41.1,73.1)$ \\
\hline $\begin{array}{l}\text { Psoriasis-involved } \\
\text { BSA }(\%), \text { mean } \\
(95 \% \mathrm{Cl})\end{array}$ & $10.0(8.6,11.4)$ & $7.7(6.3,9.1)$ & $4.7(3.8,5.7)$ & $2.4(1.8,2.9)$ \\
\hline $\begin{array}{l}\text { Achievement of } \\
\mathrm{LEI}=0^{\dagger}, \%\end{array}$ & NA & 38 & 50 & 58 \\
\hline $\begin{array}{l}\text { Achievement of dac- } \\
\text { tylitis count }=0^{\dagger} \%\end{array}$ & NA & 48 & 71 & 88 \\
\hline $\begin{array}{l}\text { PsAID score, mean } \\
\qquad(95 \% \mathrm{Cl})\end{array}$ & $5.33(5.12,5.53)$ & $4.65(4.41,4.89)$ & $3.97(3.73,4.20)$ & $3.22(2.94,3.50$ \\
\hline
\end{tabular}

*Based on the number of patients with data available at the given visit; the $n$ may vary for individual parameters at a given visit. $\dagger$ In patients affected at $\mathrm{BL}$. $\mathrm{Cl}=$ confidence interval; $\mathrm{NA}=$ not applicable.
Disclosure of Interests: Jürgen Wollenhaupt Grant/research support from: Abbott, BMS, MSD, Pfizer, UCB - grant/research support, Consultant of: Abbott, BMS, MSD, Pfizer, UCB - consultant, Harald Strothmeyer: None declared Michael Fiene: None declared, Stephan Morys Employee of: Amgen Inc. employment; Celgene $\mathrm{GmbH}$ - employment at the time of study conduct, Christian Bach Employee of: Amgen Inc. - employment; Celgene GmbH - employment at the time of study conduct, Josefine Roemmler-Zehrer Employee of: Amgen Inc. - employment; Celgene $\mathrm{GmbH}$ - employment at the time of study conduct DOI: 10.1136/annrheumdis-2020-eular.2924

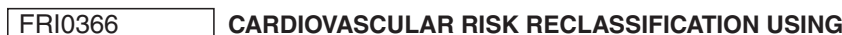 CAROTID ULTRASOUND IN PSORIATIC ARTHRITIS: A CASE-CONTROL STUDY}

D. Á. Galarza-Delgado ${ }^{1}$, J. R. Azpiri-López ${ }^{2}$, I. J. Colunga-Pedraza ${ }^{1}$, D. E. Flores Alvarado ${ }^{1}$, O. Ilizaliturri Guerra' ${ }^{1}$ I. C. Zárate Salinas ${ }^{2}$, P. F. Frausto Lerma ${ }^{1}$, A. Pérez Villar ${ }^{2}$, M. A. Reyes Soto ${ }^{1}$, A. C. Garza Acosta ${ }^{3} .{ }^{1}$ Hospital Universitario "Dr. José Eleuterio González", UANL, Rheumatology, Monterrey, Mexico; ${ }^{2}$ Hospital Universitario “Dr. José Eleuterio González," UANL, Cardiology, Monterrey, Mexico; ${ }^{3}$ Hospital Universitario “Dr. José Eleuterio González”, UANL, Radiology, Monterrey, Mexico

Background: Patients with psoriatic arthritis (PsA) have an increased risk of cardiovascular disease (CVD). Risk stratification algorithms for general population, such as cardiovascular risk calculators, have been developed to improve primary prevention and early detection of CVD; however, it underestimates cardiovascular risk in PsA patients ${ }^{1}$. Carotid ultrasound, which measures both carotid intima-media thickness (cIMT) and carotid plaque (CP), is useful in the detection of subclinical carotid atherosclerosis improving risk stratification.

Objectives: This study aimed to evaluate the use of carotid ultrasound in the reclassification of cardiovascular risk in PsA patients and compare it with controls.

Methods: This cross-sectional study included 70 PsA patients that fulfilled the CASPAR criteria and 70 controls subjects matched by age and comorbidities. Patients with a history of previous atherosclerotic CVD and pregnancy were excluded. Clinical examination, blood tests and Framingham Risk Score Lipids and BMI based (FRS-Lipids/FRS-BMI) and ACC/AHA 2013 calculators were performed. Carotid B-mode ultrasonography was used for measurements of CIMT and CP presence. Increased CIMT was defined as $\geq 0.9 \mathrm{~mm}$. CP was defined as a focal narrowing $\geq 0.5 \mathrm{~mm}$ of the surrounding lumen or a c/MT $\geq 1.2 \mathrm{~mm}$. Descriptive analysis was done with measures of central tendency and dispersion and comparisons with Chi-square, Student's t and Mann-Whitney $U$ tests.

Results: A total of 138 subjects were included. Clinical and demographic characteristics are shown in Table 1. Differences were found in the cardiovascular risk classification between the calculators and the carotid ultrasound. However, these were not significant when compared to controls, with the exception of the FRS-Lipids which had a significant difference when recategorized as high risk by the increase in the cIMT $(p=0.016)$. A $70.8 \%$ and a $56 \%$ of patients with PsA who had CP were not classified as high risk according to FRS-Lipids $(p=0.010)$ and ACC / AHA $2013(p<0.001)$ respectively.

Table 1. Clinical and demographic characteristics.

\begin{tabular}{lccc}
\hline & $\begin{array}{c}\text { PsA } \\
(\mathrm{n}=69)\end{array}$ & $\begin{array}{c}\text { Controls } \\
(\mathrm{n}=69)\end{array}$ & $\mathrm{P}$ \\
\hline Age, $($ mean \pm SD) & $53.58 \pm 10.946$ & $53.86 \pm 7.313$ & $\mathrm{NS}$ \\
Women, $\mathrm{n}(\%)$ & $38(55.1)$ & $59(85.5)$ & $<0.001$ \\
Type 2 Diabetes Mellitus, $\mathrm{n}(\%)$ & $14(20.3)$ & $9(13)$ & $\mathrm{NS}$ \\
Hypertension, $\mathrm{n}(\%)$ & $27(39.1)$ & $19(27.5)$ & $\mathrm{NS}$ \\
Dyslipidemia, $\mathrm{n}(\%)$ & $29(42)$ & $24(34.8)$ & $\mathrm{NS}$ \\
Obese, $\mathrm{n}(\%)$ & $26(37.7)$ & $28(40.6)$ & $\mathrm{NS}$ \\
Active smoker, $\mathrm{n}(\%)$ & $15(21.7)$ & $12(17.4)$ & $\mathrm{NS}$ \\
Disease duration, median (q25-q75) & $5(2.5-8)$ & - & - \\
DAS28-ESR, (mean \pm SD) & $3.74 \pm 1.477$ & - & - \\
DAPSA, median (q25-q75) & $35(27.5-58.5)$ & - & - \\
\hline
\end{tabular}

Conclusion: None of the traditional calculators used in the general population correctly estimates cardiovascular risk in patients with PsA. Among the calculators we performed, FRS-Lipids was the worst, underestimating PsA individuals with $\mathrm{CP}$ up to $70.8 \%$. Therefore, it is advisable to perform a carotid ultrasound without relying on the results obtained by any of these calculators in order to achieve an adequate classification and accomplish a correct management of the disease.

\section{References:}

[1] Sobchak, C. et al. (2019), Value of Carotid Ultrasound in Cardiovascular Risk Stratification in Patients with Psoriatic Disease. Arthritis Rheumatology, 71: 1651-1659. doi:10.1002/art.40925 